\title{
Investigation on the energy and air distribution efficiency with improved data centre cooling to support high-density servers
}

\author{
Jinkyun Cho ${ }^{1, *}$, Yongdae Jeong ${ }^{1}$, Beungyong Park ${ }^{1}$, Sangmoon Lee ${ }^{1}$ \\ ${ }^{1}$ Energy \& Environment Business Division, Korea Conformity Laboratories (KCL), Jincheon, 27872, South Korea
}

\begin{abstract}
Cooling has become a key issue in data centers where cooling accounts for about $40 \%$ of total energy usage. This study evaluated the energy and thermal performance of two data center cooling approaches: row-based cooling and room-based cooling. This research examines the temperature and humidity distribution and air distribution efficiency of an IT environment using field measurements and six performance indices. According to the observations and index evaluation results, we suggest that a rowbased cooling strategy is more efficient for server cooling. Air management helps to reduce cooling energy by enhancing optimal operation and improving cooling system efficiency.
\end{abstract}

\section{Introduction}

The increasing power usage and removal of heat generated from IT equipment have been the main issues of data centers (hereafter "DC"). Except for IT equipment, cooling (38\%) and power supply and distribution (9\%) typically account for the major proportion of energy usage in a DC. [1] The majority of power supplied to IT equipment in a DC is converted to heat, which must be removed to prevent IT equipment from overheating. To solve this problem, room-based and row-based cooling systems have been developed (Fig. 1). Room-based cooling is inefficient and thus unsuitable for next generation DCs. For a high-density IT server, a row-based cooling system should be considered as it can provide optimal air flow to the heat source. The main goal of this study is to evaluate the improvement in DC cooling efficiency according to the IT environment of the DC by comparing room-and rowbased cooling systems. To achieve this goal, cooling efficiency evaluation methods are investigated and quantitative evaluation indices are analysed, which reflect the unique characteristics of a DC. Finally, the room-based cooling system of a pilot DC is changed to a row-based cooling system, on-site measurement of the IT environment is conducted, and then the results are applied to a performance index to objectively compare system efficiencies.

\section{Evaluation DC cooling efficiency}

Many researchers have proposed evaluation indices for DC cooling efficiency [2]. Sharma et al. [3] proposed the SHI (Supply Heat Index) and RHI (Return Heat Index) to evaluate the efficient use and re-circulation of cooling air in a cooling path. However, both SHI and RHI are based on room-level units and thus are not effective for units of IT equipment. $\beta$ is another evaluation index based on room-level units that provides information about overheating to analyze the re-circulation of cooling air. Herrlin [4] presented the RCI (Rack Cooling Index) to measure the cooling performance of IT equipment, which is divided into $\mathrm{RCI}_{\mathrm{Hi}}$ and $\mathrm{RCI}_{\mathrm{Lo}}$ according to upper and lower temperature limits. The ASHRAE guideline [5] considers RCI to be very important as this index uses units of IT equipment to evaluate the thermal performance of IT equipment. Herrlin [6] proposed the RTI (Return Temperature Index) to explain air re-circulation and by-pass. The ideal condition of RTI is a $100 \%$ match between the supply and utilization of cooling air. Any RTI below 100\% indicates some by-pass of cooling air returning to the $\mathrm{CRAC} / \mathrm{H}$ unit without being used. On the other hand, any RTI above $100 \%$ indicates re-circulation of cooling air.

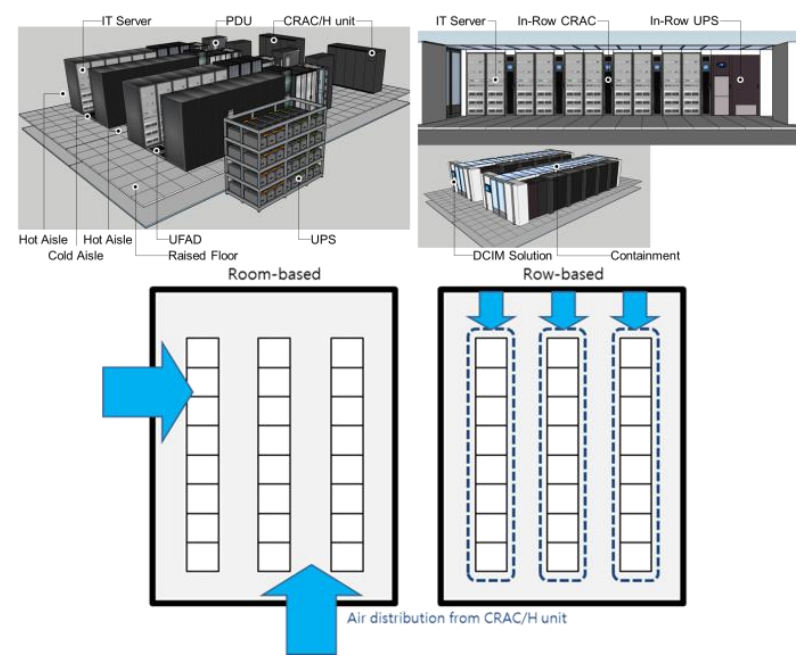

Fig. 1. Floor plans showing the basic concept of room- and row-based cooling.

Corresponding author: maxjcho@yonsei.ac.kr 
Table 1. Existing evaluation metrics of DC thermal management

\begin{tabular}{|c|c|c|c|c|}
\hline Metrics & Information & \multicolumn{2}{|c|}{ Rating } & Formula \\
\hline \multirow{2}{*}{ SHI } & Recirculation & Target & 0 & \multirow{4}{*}{$\begin{array}{l}\text { SHI (1) } \\
\text { RHI (2) }\end{array}$} \\
\hline & degree in air mixing & Good & $<0.2$ & \\
\hline \multirow{2}{*}{ RHI } & \multirow{2}{*}{$\begin{array}{l}\text { Cooling effect of } \\
\text { cold air supply }\end{array}$} & Target & 1 & \\
\hline & & Good & $>0.8$ & \\
\hline \multirow{2}{*}{$\mathrm{RCI}_{\mathrm{Lo}}$} & \multirow{2}{*}{$\begin{array}{l}\text { Rack cooling condition } \\
\text { according to cold } \\
\text { threshold values }\end{array}$} & Ideal & $100 \%$ & \multirow{4}{*}{$\begin{array}{l}\mathrm{RCI}_{\mathrm{Lo}}(5) \\
\mathrm{RCI}_{\mathrm{Hi}}(6)\end{array}$} \\
\hline & & Good & $\geq 96 \%$ & \\
\hline \multirow{2}{*}{$\mathrm{RCI}_{\mathrm{Hi}}$} & \multirow{2}{*}{$\begin{array}{l}\text { Rack cooling condition } \\
\text { according to hot } \\
\text { threshold values }\end{array}$} & Acceptable & $91 \% \sim 95 \%$ & \\
\hline & & Poor & $\leq 90 \%$ & \\
\hline \multirow{4}{*}{ RTI } & \multirow{4}{*}{$\begin{array}{l}\text { Extend of bypass } \\
\text { and recirculation }\end{array}$} & Re-circulation & $>100 \%$ & \multirow{4}{*}{ (7) } \\
\hline & & By-pass & $<100 \%$ & \\
\hline & & Acceptable & $\begin{array}{c}105 \%> \\
>95 \%\end{array}$ & \\
\hline & & Poor & $\begin{array}{l}>130 \% \\
70 \%>\end{array}$ & \\
\hline$\beta$ & $\begin{array}{l}\text { Recirculation and } \\
\text { overheating extent }\end{array}$ & Target & 0 & (8) \\
\hline
\end{tabular}

$$
\begin{aligned}
& S H I=\left[\frac{\delta Q}{Q+\delta Q}\right] \quad(1) \quad R H I=\left[\frac{Q}{Q+\delta Q}\right] \\
& Q=\sum_{j} \sum_{i} m_{i, j}^{r a c k} C_{\rho}\left[\left(T_{h}^{r a c k}\right)_{i, j}-\left(T_{s}^{r a c k}\right)_{i, j}\right] \\
& \delta Q=\sum_{j} \sum_{i} m_{i, j}^{r a c k} C_{\rho}\left[\left(T_{s}^{r a c k}\right)_{i, j}-T_{c}\right] \\
& R C I_{L o}=\left[1-\frac{\sum\left(T_{\text {Min-rec }}-T_{x}\right)_{x}<T_{\text {Min-rec }}}{\left(T_{\text {Min-rec }}-T_{\text {Min-allow }}\right) \times n}\right]
\end{aligned}
$$

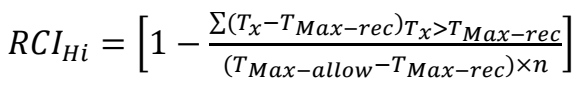

$$
\begin{aligned}
& R T I=\left[\frac{T_{R A}-T_{S A}}{\Delta T_{\text {Equip }}}\right] \\
& \beta=\frac{T_{S}-T_{C}}{T_{h}-T_{S}}
\end{aligned}
$$

\section{Measurement of IT environment and evaluation of cooling performance}

\subsection{Method and overview of field experiment}

A pilot test for improving the cooling performance of medium-scale DC (GFA: $735 \mathrm{~m}^{2}$ ) was performed.
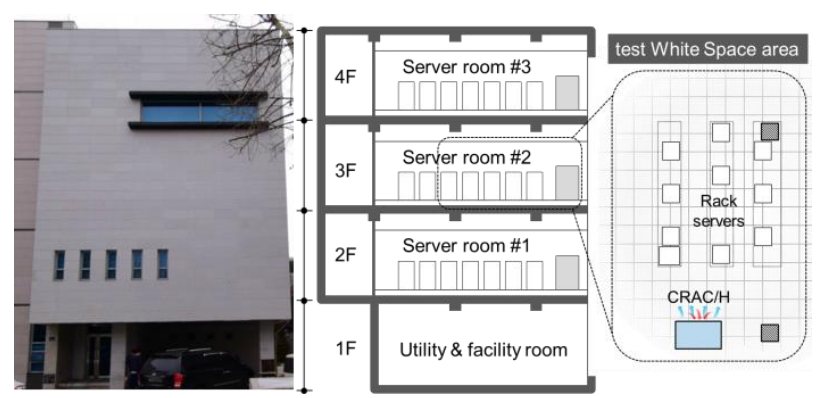

Fig. 2. Reference DC of the case study for pilot test.
As shown in Fig. 2, three out of four floors contained server rooms, and a room-based cooling system was currently in operation. Measurement of the IT environment was limited to a zone of the IT server room on the third floor. This was because the room-based cooling system was due to be replaced with a row-based cooling system to comparatively evaluate the cooling performance. A single unit rack consisted of eight IT servers. Each IT server had a power consumption of 870 $\mathrm{W}$ and a fan air flow rate of $258 \mathrm{~m}^{3} / \mathrm{h}$. The cooling load was at least $95 \%$ of the power consumption. Each rack had a cooling load of approximately $7.0 \mathrm{~kW} /$ rack and the required air flow of $2000 \mathrm{~m}^{3} / \mathrm{h}$. (Fig. 3) Six rack servers were applied to the new row-based cooling system, which required a cooling capacity of $40 \mathrm{~kW}$. Fig. 4 shows the DC under analysis, the measurement zone of the IT environment on the third floor, and the sensor locations. The IT server room did not adopt the cooling system with raised floor but had a hard floor where cold air was distributed directly from the $\mathrm{CRAC} / \mathrm{H}$ unit. Temperature and humidity were measured at rack (A), located far from the $\mathrm{CRAC} / \mathrm{H}$ unit and at another rack (B), located near the $\mathrm{CRAC} / \mathrm{H}$ unit. The ten measurement points included the upper and lower inlets (4), the upper and lower outlets (4), the SA (supply air) of the $\mathrm{CRAC} / \mathrm{H}$ unit, and the RA (return air) form IT room. Measurements were continuously conducted for 3 days every $10 \mathrm{~min}$.

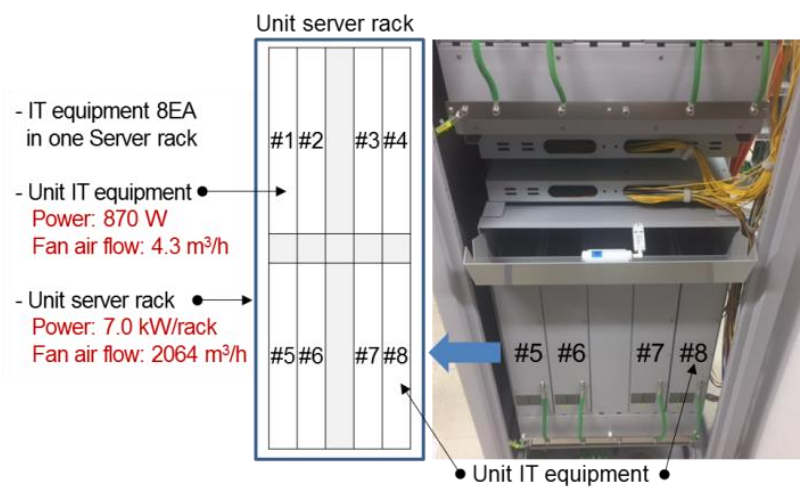

Fig. 3. Rack server configurations of the IT equipment.

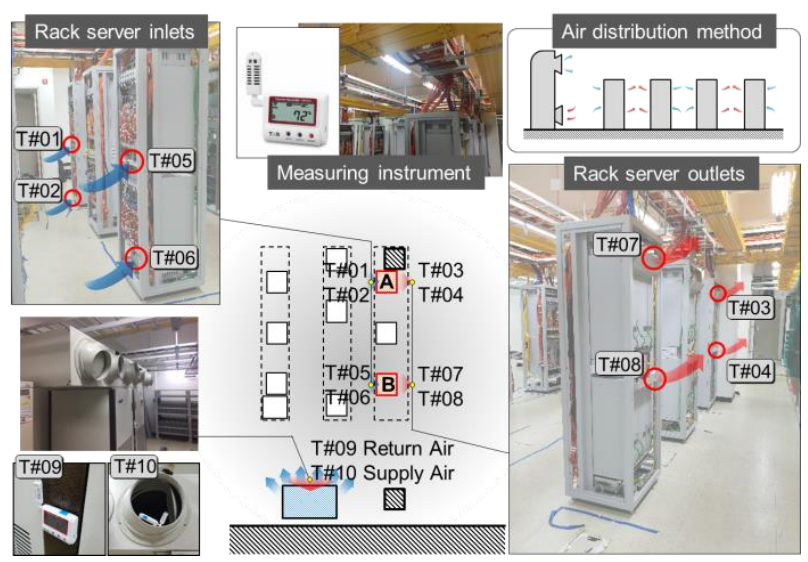

Fig. 4. On-site temperature and humidity measurement points for an IT environment of the room-based cooling system. 
Table 2. Measured IT environment of the room-based cooling.

\begin{tabular}{|c|c|c|c|c|}
\hline \multicolumn{2}{|c|}{$\begin{array}{c}\text { Average } \\
\text { IT environment }\end{array}$} & $\begin{array}{c}\text { Air } \\
\text { temperature } \\
\left({ }^{\circ} \mathbf{C}\right)\end{array}$ & $\begin{array}{c}\text { Relative } \\
\text { humidity } \\
(\%)\end{array}$ \\
\hline \multirow{3}{*}{$\begin{array}{c}\text { Rack } \\
\text { A }\end{array}$} & $\begin{array}{c}\text { Inlet } \\
\text { (upper/lower) }\end{array}$ & $\mathrm{T} \# 01$ & 25.68 & 33.46 \\
\cline { 2 - 5 } & $\begin{array}{c}\text { Outlet } \\
\text { (upper/lower) }\end{array}$ & $\mathrm{T} \# 02$ & 23.60 & 38.82 \\
\cline { 3 - 5 } & $\mathrm{T} \# 03$ & 37.10 & 16.39 \\
\hline \multirow{3}{*}{$\begin{array}{c}\text { Rack } \\
\text { B }\end{array}$} & $\begin{array}{c}\text { Inlet } \\
\text { (upper/lower) }\end{array}$ & $\mathrm{T} \# 05$ & 43.42 & 11.04 \\
\cline { 3 - 5 } & $\begin{array}{c}\text { Outlet } \\
\text { (upper/lower) }\end{array}$ & $\mathrm{T} \# 06$ & 23.87 & 35.94 \\
\cline { 3 - 5 } & $\mathrm{T} \# 08$ & 38.33 & 39.17 \\
\hline \multicolumn{2}{|c|}{ Return Air (Room air) } & $\mathrm{T} \# 09$ & 23.97 & 15.02 \\
\hline \multicolumn{2}{|c|}{ Supply Air from CRAC } & $\mathrm{T} \# 10$ & 15.79 & 64.47 \\
\hline
\end{tabular}

\subsection{Room-based server cooling system analysis}

\subsubsection{Distribution of temperature and humidity}

In the IT environment of the room-based server cooling system, as shown in Table 2 and Fig. 5, the average SA temperature of the $\mathrm{CRAC} / \mathrm{H}$ unit $(\mathrm{T} \# 10)$ was $15.79^{\circ} \mathrm{C}$ and the average temperature of air inlets from the cold aisle to the rack serves ( $\mathrm{T} \# 01, \mathrm{~T} \# 02, \mathrm{~T} \# 05, \mathrm{~T} \# 06$ ) was $24.1^{\circ} \mathrm{C}$. A loss of at least $8.3^{\circ} \mathrm{C}$ was measured along the distribution path. In addition, the average temperature of air outlets (T\#03, T\#04, T\#07, T\#08) to the hot aisle after removing heat in the rack server was $39.9^{\circ} \mathrm{C}$. In other words, a change in temperature, $\Delta \mathrm{T}$, of $15.8^{\circ} \mathrm{C}$ was maintained. However, the average RA temperature of the $\mathrm{CRAC} / \mathrm{H}$ unit $(\mathrm{T} \# 09)$ was $24.0^{\circ} \mathrm{C}$, indicating serious mixing of air in the room. As the temperature distribution was not affected by external factors such as building skin load but mostly by the thermal load of the equipment, it remained steady [7]. Nevertheless, as the average temperature of the cold aisle was higher than the average RA temperature, the air of the hot aisle was recirculated or mixed substantially in many parts. Relative humidity does not have a significant effect on cooling efficiency; however, as the IT equipment may be affected by low relative humidity, this parameter should still be considered. A relative humidity of approximately $35 \%$ was maintained in the cold aisle, which satisfied the permissible range of ASHRAE Class A-1 $(\mathrm{RH}(8 \sim 80 \%))$. However, when heat was removed and temperature increased in the hot aisle, the relative humidity was approximately $15 \%$. Accordingly, humidification could be considered if the relative humidity decreased further.

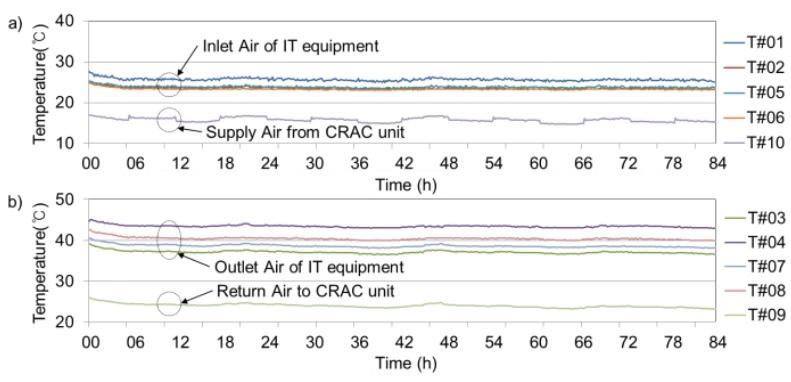

Fig. 5. On-site temperature distributions around IT equipment for the room-based cooling system: a) inlet air and b) outlet air.

\subsubsection{Evaluation of cooling efficiency}

The analysis of IT environmental factors (temperature) through on-site measurement is key for deriving a quantitative index using evaluation metrics for the cooling efficiency of a DC. The DC used in this study did not adopt a raised floor for air supply in the roombased cooling system of the server room. SHI, RHI, RCI, RTI, and $\beta$, all of which could be calculated, were analyzed. Fig. 6 shows the continuous distribution of performance metrics during measurement of the IT environment. As presented in Table 3, the cooling efficiency was analyzed using objective metrics or based on the criteria and results of each metric. SHI and RHI, which are dimensionless metrics with respect to the mixing of air emitted from the IT equipment and low temperature cooling air and heat loss, are complementary to each other. The distribution of SHI was $0.31-0.37$ (Target: 0.0), and that of RHI was 0.63-0.69 (Target: 1.0). Thus, neither index exhibited appropriate performance. On the other hand, RCI maintained an appropriate temperature within the permissible temperature range of ASHRAE Class A-1 for a server room. $\mathrm{RCI}_{\mathrm{Lo}}$ evaluates whether an adequate thermal environment is maintained within the recommended temperature range $\left(18-27^{\circ} \mathrm{C}\right)$ and the range of allowable temperature $\left(15-32^{\circ} \mathrm{C}\right)$. An optimal condition is maintained within an $100 \%$ permissible temperature range in every inlet. $\mathrm{RCI}_{\mathrm{Hi}}$, which represents the opposite concept, evaluates whether an appropriate thermal environment is maintained within the lower range. The permissible temperature is maintained in the range of $89.3-100 \%$. This level causes no specific problems to the thermal environment. RTI can measure the energy performance of a cooling system. The ratio between the temperature rise in SA and RA of the $\mathrm{CRAC} / \mathrm{H}$ unit and that of the cooling air with heat removed after the IT equipment is the evaluation criterion. RTI was $47 \sim 56 \%$, indicating substantial by-pass. In other words, cooling air from the $\mathrm{CRAC} / \mathrm{H}$ unit could not pass through the IT equipment but was instead returned to the $\mathrm{CRAC} / \mathrm{H}$ unit. More air than required by the rack server was supplied and a large portion was lost, which resulted in energy inefficiency.

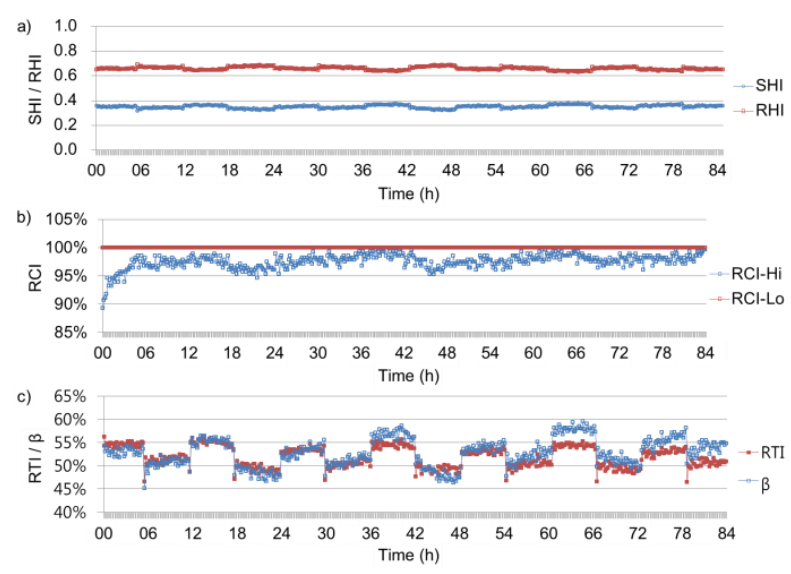

Fig. 6. Effect of the uncontained layout on evaluation metrics for room-based cooling; a) SHI and RHI, b) $\mathrm{RCI}_{\mathrm{Hi}}$ and $\mathrm{RCI}_{\mathrm{Lo}}$, and c) RTI and $\beta$. 
Table 3. Results of evaluation metrics for thermal management (room-based cooling).

\begin{tabular}{|c|c|c|c|}
\hline Metrics & \multicolumn{2}{|c|}{ Rating } & Results \\
\hline \multirow{2}{*}{ SHI } & Target & 0 & \multirow{2}{*}{0.35} \\
\hline & Good & $<0.2$ & \\
\hline \multirow{2}{*}{ RHI } & Target & 1 & \multirow{2}{*}{0.65} \\
\hline & Good & $>0.8$ & \\
\hline \multirow{4}{*}{$\mathrm{RCI}_{\mathrm{Lo}}$} & Ideal & $100 \%$ & \multirow{4}{*}{$100 \%$ (Ideal) } \\
\hline & Good & $\geq 96 \%$ & \\
\hline & Acceptable & $91 \% \sim 95 \%$ & \\
\hline & Poor & $\leq 90 \%$ & \\
\hline \multirow{4}{*}{$\mathrm{RCI}_{\mathrm{Hi}}$} & Ideal & $100 \%$ & \multirow{4}{*}{$97.5 \%$ (Good) } \\
\hline & Good & $\geq 96 \%$ & \\
\hline & Acceptable & $91 \% \sim 95 \%$ & \\
\hline & Poor & $\leq 90 \%$ & \\
\hline \multirow{4}{*}{ RTI } & Re-circulation & $>100 \%$ & \multirow{4}{*}{$\begin{array}{c}\text { By-pass: } \\
51.9 \% \text { (Poor) }\end{array}$} \\
\hline & By-pass & $<100 \%$ & \\
\hline & Acceptable & $105 \%>,>95 \%$ & \\
\hline & Poor & $>130 \%, 70 \%>$ & \\
\hline$\beta$ & Target & 0 & $52.8 \%$ \\
\hline
\end{tabular}

$\beta$ is also used to determine recirculation and overheating; an inefficiency range of $45-60 \%$ was maintained. Based on the above indices, the room-based cooling system of the DC showed loss in the cooling distribution path, mixing of cooling air, and inefficient air by-pass. In addition, significant inefficiency resulted from the need to supply additional cooling energy to maintain an appropriate IT environment for RCI.

\subsection{Row-based server cooling system analysis}

\subsubsection{Application and measurement method of the row-based server cooling system}

A part of the room-based server cooling system was replaced with a row-based cooling system to compare the resulting IT environment. The cooling performance was evaluated both before and after measurement. As shown in Fig. 7, containments were installed in both the cold aisle and hot aisle to distinguish the zone where six rack servers were arranged and three small-capacity $\mathrm{CRAC} / \mathrm{H}$ units were installed. The temperature and humidity of the inlet and outlet of each server rack were measured at the same locations as for the room-based cooling system. Measurements were continuously conducted for 3 days every $10 \mathrm{~min}$ at 10 points including the SA (cold aisle) and RA (hot aisle) of a representative $\mathrm{CRAC} / \mathrm{H}$ unit.

\subsubsection{Distribution of temperature and humidity}

To maintain the cold aisle of the row-based cooling system at $25^{\circ} \mathrm{C}$, three $\mathrm{CRAC} / \mathrm{H}$ units were set to start and stop and the fan was set to operate continuously. In the IT environment, as shown in Table 4 and Fig. 8, the average SA temperature of the CRAC/H unit (T\#10) was $21.2^{\circ} \mathrm{C}$ and the average temperature of air flowing from the cold aisle to the rack servers $(\mathrm{T} \# 01, \mathrm{~T} \# 02, \mathrm{~T} \# 05$, $\mathrm{T \# 06)}$ was $25.78^{\circ} \mathrm{C}$.

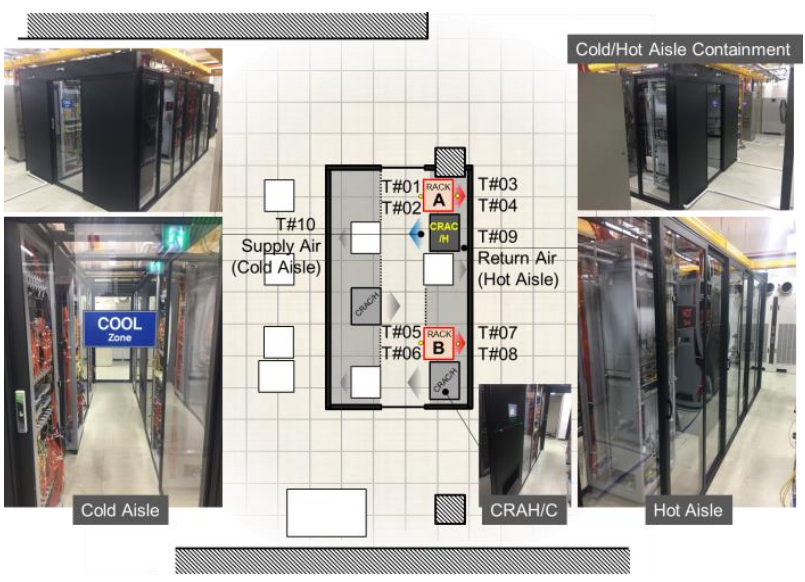

Fig. 7. On-site temperature and humidity measurement points of the IT environment for the row-based cooling system.

Thus, approximately $4.5^{\circ} \mathrm{C}$ was lost along the distribution path, making this system at least $50 \%$ more effective than the room-based cooling system. In addition, the average temperature of air ( $\mathrm{T} \# 03$, T\#04, $\mathrm{T} \# 0$ 7, $\mathrm{T} \# 08$ ) emitted to the hot aisle after heat removal in the rack server was $41.5^{\circ} \mathrm{C}$. In other words, approximately $\Delta \mathrm{T}=15.7^{\circ} \mathrm{C}$ was maintained, which was similar to the room-based cooling system. Moreover, the average RA temperature ( $\mathrm{T} \# 09)$ of the $\mathrm{CRAC} / \mathrm{H}$ unit was $33.8^{\circ} \mathrm{C}$, indicating that mixing of air in the cold aisle was significantly improved. As the temperature of the cold aisle was at least $10^{\circ} \mathrm{C}$ less than the RA temperature, the mixing of recirculated air in the hot aisle was also improved. The distribution of relative humidity was similar to that of the room-based cooling system.

Table 4. Measured IT environment of the row-based cooling.

\begin{tabular}{|c|c|c|c|c|}
\hline \multicolumn{3}{|c|}{$\begin{array}{c}\text { Average } \\
\text { IT environment }\end{array}$} & $\begin{array}{c}\text { Air } \\
\text { temperature } \\
\left({ }^{\circ} \mathbf{C}\right)\end{array}$ & $\begin{array}{c}\text { Relative } \\
\text { humidity } \\
(\%)\end{array}$ \\
\hline \multirow{3}{*}{$\begin{array}{c}\text { Rack } \\
\text { A }\end{array}$} & $\begin{array}{c}\text { Inlet } \\
\text { (upper/lower) }\end{array}$ & $\mathrm{T} \# 01$ & 24.05 & 32.14 \\
\cline { 3 - 5 } & $\begin{array}{c}\text { Outlet } \\
\text { (upper/lower) }\end{array}$ & $\mathrm{T} \# 02$ & 26.22 & 35.15 \\
\cline { 3 - 5 } & T\#03 & T\#04 & 47.96 & 17.04 \\
\hline \multirow{3}{*}{$\begin{array}{c}\text { Rack } \\
\text { B }\end{array}$} & $\begin{array}{c}\text { Inlet } \\
\text { (upper/lower) }\end{array}$ & $\mathrm{T} \# 05$ & 26.40 & 11.98 \\
\cline { 3 - 5 } & Outlet & $\mathrm{T} \# 06$ & 26.44 & 34.11 \\
\cline { 3 - 5 } & (upper/lower) & $\mathrm{T} \# 07$ & 41.13 & 14.15 \\
\cline { 3 - 5 } & $\mathrm{T} \# 08$ & 44.73 & 11.96 \\
\hline \multicolumn{2}{|c|}{ Return Air (Hot aisle) } & $\mathrm{T} \# 09$ & 33.81 & 21.22 \\
\hline \multicolumn{2}{|c|}{ Supply Air (Cold aisle) } & $\mathrm{T} \# 10$ & 21.24 & 36.52 \\
\hline
\end{tabular}

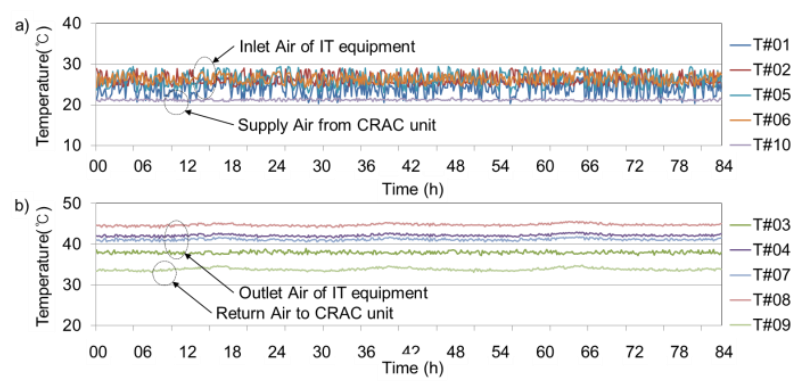

Fig. 8. On-site temperature distributions around IT equipment for the row-based cooling system: a) inlet air and b) outlet air. 


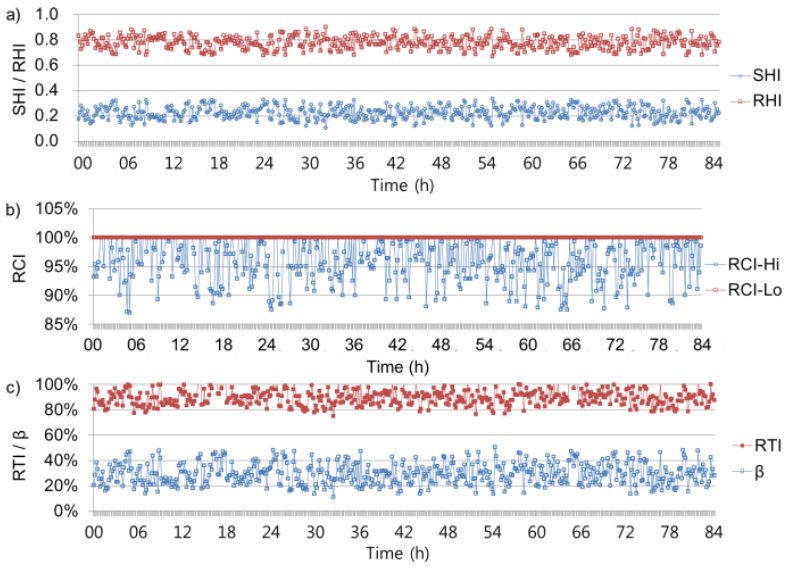

Fig. 9. Effect of the uncontained layout on evaluation metrics for row-based cooling; a) SHI and RHI, b) $\mathrm{RCI}_{\mathrm{Hi}}$ and $\mathrm{RCI}_{\mathrm{Lo}}$, and c) RTI and $\beta$.

\subsubsection{Evaluation of cooling efficiency}

As for the room-based cooling system, the cooling efficiency of the row-based server cooling system was analyzed using SHI, RHI, RCI, RTI, and $\beta$. Fig. 9 shows the continuous distribution of performance metrics during measurement of the IT environment. As presented in Table 5, the cooling efficiency was analyzed using objective metrics or the criteria and results of each metric. The average SHI and RHI were 0.22 and 0.78 , respectively. Both results approximated the appropriate performance and indicated improvements of $37.1 \%$ and $20.0 \%$, respectively, compared to the room-based cooling system. RCI also maintained an adequate temperature despite the increase of inlet temperature in the $\mathrm{CRAC} / \mathrm{H}$ unit. $\mathrm{RCI}_{\mathrm{Lo}}$ maintained an optimal condition within a $100 \%$ permissible temperature range in all air inlet of IT servers. $\mathrm{RCI}_{\mathrm{Hi}}$, which is the opposite concept, decreased slightly in the average lower range of $96.3 \%$ but maintained an appropriate temperature. The average RTI was $90 \%$, which indicated some by-pass but was within an appropriate range for the operating environment. This value was also a $73.2 \%$ improvement over that of the room-based cooling system. Although the containment was applied to both cold and hot aisles, the airtightness was not high enough; thus, some of the cooling air supplied by the $\mathrm{CRAC} / \mathrm{H}$ unit did not pass through the IT equipment but was instead returned to the unit. $\beta$, which was used to judge recirculation and overheating, was $29.4 \%$ on average, which approximated an efficient range and also a $44.3 \%$ improvement over that of the room-based cooling system. By analysing the cooling efficiency of the row-based cooling system with full containment of cold and hot aisles using the six indices, losses in the distribution path and the mixing and by-pass of cooling air can be minimized and the inlet temperature of the $\mathrm{CRAC} / \mathrm{H}$ unit can be maintained at a high level. Thus, the equipment efficiency (e.g. COP) of the cooling system can be effectively improved. Moreover, if a small-capacity fan with a low static pressure replaces the large-capacity, high-static pressure fan, the power consumption of the fan can be effectively reduced.
Table 5. Results of evaluation metrics for thermal management (row-based cooling).

\begin{tabular}{|c|c|c|c|}
\hline \multirow{2}{*}{ Metrics } & \multicolumn{2}{|c|}{ Results } & \multirow{2}{*}{$\begin{array}{l}\text { Percentage } \\
\text { difference }\end{array}$} \\
\hline & Room-based & Row-based & \\
\hline SHI & 0.35 & 0.22 & $-37.1 \%$ \\
\hline RHI & 0.65 & 0.78 & $20.0 \%$ \\
\hline $\mathrm{RCI}_{\mathrm{Lo}}$ & $\begin{array}{l}100 \% \\
\text { (Ideal) }\end{array}$ & $\begin{array}{c}100 \% \\
\text { (Ideal) }\end{array}$ & - \\
\hline $\mathrm{RCI}_{\mathrm{Hi}}$ & $\begin{array}{l}97.5 \% \\
\text { (Good) }\end{array}$ & $\begin{array}{l}96.3 \% \\
\text { (Good) }\end{array}$ & $-1.2 \%$ \\
\hline RTI & $\begin{array}{l}\text { By-pass: } 51.9 \% \\
\text { (Poor) }\end{array}$ & $\begin{array}{c}\text { By-pass: } 89.9 \% \\
\text { (Acceptable) }\end{array}$ & $29.4 \%$ \\
\hline$\beta$ & $52.8 \%$ & $73.2 \%$ & $-44.3 \%$ \\
\hline
\end{tabular}

\section{Conclusions}

The main goal of this study was to analyze the improvement in cooling system efficiency by comparing room-and row-based cooling systems according to the IT environment and energy use characteristics of a data center. To achieve this goal, the room-based cooling system of the data center under analysis was changed to a row-based cooling system. First, we used quantitative evaluation indices to reflect the characteristics of the center. Then, we performed on-site measurement of the IT environment and applied the measurement results to performance indices. In this way, the two system efficiencies were objectively compared.

(1) The IT environment of the room-based server cooling system was measured in a medium scale data center. Various evaluation indices were analyzed based on the temperature and relative humidity of the inlet/outlet air of IT equipment and of the CRAC unit.

(2) The cooling energy efficiency was analyzed using six indices (SHI, RHI, RCI, RTI, and $\beta$ ). The roombased cooling system exhibited inefficient operation such as losses in the distribution path and the mixing and by-pass of cooling air. Thus, the room-based cooling system was more inefficient as more cooling energy was required to maintain an appropriate IT environment.

(3) For the full containment of cold and hot aisles, the efficiency of the row-based cooling system was better than that of the room-based cooling system. In other words, SHI and RHI were improved by $37.1 \%$ and $20.0 \%$, respectively, and RTI and $\beta$ were improved by $73.2 \%$ and $44.3 \%$, respectively.

(4) In future work, a sensitivity analysis should be performed for the decrease in cooling energy at various inlet temperatures.

Evaluating cooling efficiency according to the configuration of the IT server room and reflecting these results in the design phase of cooling systems are key for preventing enormous energy costs being incurred during the operation of a completed data center. A comprehensive and objective analysis of the operational 
factors that influence cooling efficiency and the impact of each factor can reduce the cooling energy of a highdensity data center and allow a comparison of the cooling performance of room-based, row-based, and even rack-based systems. Consequently, a modular package solution should be provided that can flexibly apply a row-based cooling system to new or existing data centers.

This research was supported by grant of the research fund of the Korea MOTIE (Ministry of Trade, Industry and Energy) in 2018. Project number: 20182010600010.

\section{References}

1. J. Cho, J. Yang, W. Park, Energy and Buildings 68 (2014)

2. M. Xie, J. Wang, J. Liu, Applied Thermal Engineering 147 (2019)

3. R.K Sharma, C.E. Bash, C.D. Patel, American Institute of Aeronautics and Astronautics (AIAA) (2002)

4. M.K. Herrlin, ASHRAE Transactions 111(Part 2) (2005)

5. ASHRAE TC 9.9, Thermal Guideline for Data Processing Environments (American Society of Heating, Refrigerating and Air-Conditioning Engineers, Inc., Atlanta, GA, 2015)

6. M.K. Herrlin, Proceedings of Digital Power Forum (2007).

7. J. Cho, T. Lim, B.S. Kim, Energy and Buildings 41 (2009)

\begin{tabular}{|ll|}
\hline \multicolumn{2}{|l|}{ Abbreviations } \\
$C R A C / H$ & computer room air conditioning/handling \\
DCIM & data centre infrastructure management \\
Nomenclature & \\
$Q$ & heat transfer rate $[\mathrm{W}]$ \\
$T$ & temperature $\left[{ }^{\circ} \mathrm{C}\right]$ \\
$\Delta T$ & temperature differential $\left[{ }^{\circ} \mathrm{C}\right]$ \\
$m$ & air flow rate $\left[\mathrm{m}^{3} / \mathrm{h}\right]$ \\
$n$ & total number of racks \\
$C_{p}$ & specific heat $\left[\mathrm{J} / \mathrm{kg}^{\circ} \mathrm{C}\right]$ \\
Subscripts & and superscripts \\
rack & rack unit \\
$s$ & supply air to IT equipment \\
$c$ & supply air from CRAC/H \\
$h$ & exhaust air form IT equipment to hall(room) \\
$x$ & xth IT server (average) \\
Max-rec & maximum recommended/ASHRAE TC9.9 (2015) \\
Max-allow & maximum allowable/ASHRAE TC9.9 (2015) \\
Min-rec & minimum recommended/ASHRAE TC9.9 (2015) \\
Min-allow & minimum allowable/ASHRAE TC9.9 (2015) \\
SA & supply air from CRAC/H unit \\
RA & return air to CRAC/H unit \\
Equip & IT equipment \\
\hline & \\
\hline
\end{tabular}

